\title{
Verification of air brush effectiveness using cosmeceutical ingredients
}

\author{
Hyun Jung Kim, Min Sook Jung ${ }^{*}$ (D) Jeong Min Shin and Yu Kyung Hur
}

\begin{abstract}
Background: The development of the beauty industry has been accelerated by the combination of the basic desire of humans to look beautiful and the trend of the age in which the down-aging phenomenon is caused by an aging society. Previously, therapy, which has been provided by experts, has now expanded and changed its category into everyday home care. Thus, skin care devices became common and widespread. Also, public attention has been focused on functional cosmetics such as whitening and wrinkling improvements of a home care product. However, the results of validation of the effectiveness of functional components and the use of skin care devices are rare.

Methods: Middle-aged women were asked to apply $3 \mathrm{~mL}$ of ampule containing niacinamide $2 \%$ and adenosine 0. 04\% to the face twice a day, once in the morning and the other in the evening, for 4 weeks. The control group (C) was asked to apply using hands while the experimental group (E) was asked to apply using airbrush.

Results: The moisture content of the entire face has increased in all clusters, resulting from a combination of the moisture content of the niacinamide and the increase in the collagen content of the adenosine. $L^{*}$ was increased in all groups, but only E showed significant results. $a^{*}$ was increased in $C$ and showed a significant decrease in $E$ only. $b^{*}$ decreased in group $C$ and increased in group $E$. The overall size of the wrinkles, the depth of the wrinkles, and the width of the wrinkles showed significant improvements in all groups, with higher rates of improvement in $\mathrm{E}$.

Conclusions: This study produced verification results on whitening effects of niacinamide, wrinkling improvement of adenosine, and the usefulness of air brushes. Previously, dermal absorption studies on soluble ingredients of cosmetics were limited to iontophoresis, while various methods of study design on the dispensing and physical effects of fine particles were expected. It also recommends a research design approach that is practical for home care, rather than approach using a professional program on the usefulness of skin care device.
\end{abstract}

Trial registration: Korea National Institute for Bioethics Policy, P01-201711-13-002, registered 16 November 2017, http://public.irb.or.kr/.

Keywords: Airbrush, Niacinamide, Adenosine, Skin care device, Cosmeceutical ingredient

\section{Background}

Entering the 2000s, the general public identified looks as a new differentiating factor, unlike conventional factors such as race, gender, religion, and ideology. Along with this, the term lookism emerged, which refers to appearance-oriented views, through a column published in The New York Times in 2000 (Safire 2000). The criteria for the ideal "modern look" have been standardized and disseminated via mass media and are now used

\footnotetext{
* Correspondence: yunhai0540@naver.com

Dasan Skin Clinical Research Center, Dasan C \& Tech, 42, Eonju-ro 81-gil,

Gangnam-gu, Seoul 06223, Republic of Korea
}

as important tools that enable individuals to be recognized (Kim et al. 2005; Kim 2006; Lee and Kim 2015).

Moreover, South Korean society is rapidly aging. In 2020, the country's elderly population will account for over $14 \%$ of the total population. Therefore, modern Koreans who look to a centenarian era still intend to convey an image of high economic activity, regardless of their actual ages. Accordingly, this desire can drive an individual to attempt to look younger than his or her chronological age. This is referred to as the down-aging phenomenon (Jo and Hwang 2013).

(c) The Author(s). 2018 Open Access This article is distributed under the terms of the Creative Commons Attribution 4.0 International License (http://creativecommons.org/licenses/by/4.0/), which permits unrestricted use, distribution, and reproduction in any medium, provided you give appropriate credit to the original author(s) and the source, provide a link to the Creative Commons license, and indicate if changes were made. The Creative Commons Public Domain Dedication waiver (http://creativecommons.org/publicdomain/zero/1.0/) applies to the data made available in this article, unless otherwise stated. 
Down-aging has accelerated the growth of the beauty industry in conjunction with an increasing demand for physical beauty. In the past, plastic surgeons were the primary providers of a range of services, from skin care and therapies to surgical treatments. Today, these treatments have penetrated the daily home care market. Skin care devices that are popularized and widely distributed throughout the general public include exfoliating devices, vibrating cleansers, galvanic devices, and lightemitting diode (LED) masks.

In addition, there is a new emphasis on functionality in the beauty industry as exemplified by generalization of products with whitening and anti-wrinkle functions, even including cosmetics such as air cushions. In 2001, functional cosmetics were established as an official category of cosmetics through enactment of regulations thus securing a legal status (Kim et al. 2014). Along with continuous legal amendments, as of May 2017, cosmetic functionalities, which were previously limited to whitening, anti-wrinkle, and sunscreen products, were broadened to encompass cosmetics for dyeing, bleaching, hair loss prevention, acne, atopy, and stretch mark care.

While the present study used niacinamide and adenosine, which are anti-wrinkle functional substances, few domestic studies have verified the effectiveness of these ingredients outside of the whitening function. Moreover, despite the launch of a variety of new skin care devices, little research has been done on their effectiveness.

Therefore, the present study aimed to analyze the effects of functional ingredients, niacinamide and adenosine, on skin physiology using an air brush skin care device, thereby examining the overall usefulness of air brushes for skin care.

\section{Methods}

This study was approved by the Institutional Review Board of the Korea National Institute for Bioethics Policy following a comprehensive review of study-related procedures (P01-201711-13-002).

\section{Subjects}

This study involved middle-aged women in their 30s50 s, who showed symptoms of hyperpigmentation (e.g., stains, freckles) and wrinkles around the eyes. They were divided into an experimental group (group $\mathrm{E} ; n=10$ ) and a control group (group $C ; n=10$ ). The subjects were selected based on the guidelines for evaluating the effectiveness of functional cosmetics suggested by the Ministry of Food and Drug Safety (MFDS) and the results of a study conducted by Lee et al. (2013).

Exclusion criteria were as follows: (1) those who showed abnormal symptoms such as acute and chronic physical diseases involving the face, including facial skin diseases; (2) those with at least a 1-month history of facial application of a skin care product containing steroids; (3) those with medical histories of contact or photoallergic dermatitis caused by a topical ointment; and (4) those with sensitive or hypersensitive skin. In addition, the subjects were randomly divided into different clinical groups so as to minimize any variations in the experimental results.

The study was conducted between November 20, 2017, and February 5, 2018. The subjects were provided with a 3-mL test agent and instructed to apply it to their skin twice a day, once in the morning and once in the evening, over a 28 -day period. They were instructed to wash their faces, smooth out their skin with a toner, and then apply the agent on their face. Group $C$ subjects applied the test agent using their hands, whereas group E subjects applied the test agent using an air brush and left it to be absorbed without using their hands. All subjects were monitored by the researchers and were instructed to record the daily applications in a self-care chart that was later submitted to ensure compliance with test procedures. In addition, we requested they avoid other skin care or treatment modalities over the research period, including the use of cosmetics that could change their facial skin conditions. Subjects were also instructed to make no changes to their typical daily living routines. The subjects were completely informed that they should not use cosmetics that contained whitening or anti-wrinkle functional ingredients that could change their facial skin conditions during the research period, and they consented to do so. Moreover, based on a study conducted by Han et al. (2015), the subjects were allowed to use sunblock when going outside and wear light makeup and maintain their usual skin care cosmetics or makeup habits. However, they were instructed to not make any changes in their daily living patterns, such as exercise, because changes in living patterns could affect their skin conditions.

Regarding the measurement of facial skin conditions, a study conducted by Kim (2007) reported that at least $30 \mathrm{~min}$ of skin stabilization is necessary to measure all selected variables for the skin surface: temperature, color luminosity, transepidermal water loss, and oil. The study also reported that consistent measurement values could be obtained through skin stabilization regardless of environmental effects. Accordingly, skin stabilization was induced to all subjects in the present study for 30 min after facial wash, and all subjects underwent skin measurement. Nonetheless, to minimize any environmental effect, the skin measurement was performed indoors at temperatures between 20 and $24{ }^{\circ} \mathrm{C}$ and relative humidity levels between 40 and $60 \%$ based on a study conducted by Kim and Gang (2017).

All subjects underwent skin measurement before and after the experiment. All skin measures took place $30 \mathrm{~min}$ 
after facial washing to encourage skin stabilization. Additionally, group E subjects were trained by the researcher in the operation of the air brush at their first visit. The spraying method was based on the principle of lymphatic massage.

\section{Research materials}

The test agent administered to groups $\mathrm{C}$ and $\mathrm{E}$ is described in Table 1 and consisted of $2.00 \%$ niacinamide and $0.04 \%$ adenosine. Niacinamide is recognized as a whitening ingredient and adenosine as an anti-wrinkle ingredient by the MFDS. The test agent was considered safe for daily use. Niacinamide, which is used as a whitening functional ingredient, was purchased from company $\mathrm{B}$ as a $100 \%$ powder form, whereas adenosine, which is used as an anti-wrinkle functional ingredient, was purchased from company A in an undiluted form. According to the Globally Harmonized System of Classification and Labelling of Chemicals, these purchased ingredients were confirmed as identical with "niacinamide" and "adenosine" listed in the International Nomenclature of Cosmetic Ingredients. In addition, $2.00 \%$ niacinamide and $0.04 \%$ adenosine were applied to formulate the test agent in consideration of the subjects' stability pursuant to the notifications of the MFDS. The test agent was manufactured as $6 \mathrm{ml}$ ampules and was provided to the subjects to ensure easier use, which is to apply one ampule each day. The main goal of the experiment was to have the subjects use accurate volumes of the test agent.

\section{Research tools}

The air brush (M66, Dasan C \& Tech., Korea) used for this study consisted of a spray gun, air compressor, air hose, and adapter. It is shown in Fig. 1.

\section{Spray gun}

After putting liquid into the container and pulling the lever, a needle is pulled. This creates a space in the nozzle, and the liquid is mixed with the air that is injected by the compressor. This mixture of liquid and air is propelled from the device. With the spray gun used in this study, the stronger the lever is pulled, the greater is the volume of air exposure. Consequently, more liquid is sprayed. The spray gun's nozzle size is $0.35 \mathrm{~mm}$.

\section{Air compressor}

This component delivers compressed air to the spray gun. The pressure of the air that is injected by the air compressor is approximately $0.7 \mathrm{kgf} / \mathrm{cm}^{2}$.

\section{Air hose}

The air hose transmits the air from the air compressor to the spray gun, connecting the air compressor outlet with the spray gun inlet.

\section{Adapter}

Input: AC 100-240 V, 50-60 Hz, $1.5 \mathrm{~A}$.

Output: DC 13 V, 1.5 A.

The air brush is rechargeable, with a charging time of approximately $2 \mathrm{~h}$. It can be used for approximately 60 min after a single charge. The amount of battery life is indicated with LED lights.

\section{Skin measurement tools}

In this study, the SKIN-O-MAT (CORNEOMETER, SEBUMETER, SKIN-pH-METER, Cosmomed, Germany) was used to measure skin moisture levels, and the DSM II ColorMeter (DSM II ColorMeter reflectance test unit, Cortex Technology, Denmark) was used to measure skin color and luminosity. In addition, Antera 3D (Antera 3D CS, Miravex Limited, Ireland) imaged the deepest wrinkles in the lower orbit of the eye and measured wrinkle length, depth, and width.

\section{Data analysis methods}

SPSS 24.0 for Windows (IBM, New York, USA) was used to analyze all data. An independent $t$ test was performed to test homogeneity between the two groups before the experiment, and a paired $t$ test was used to analyze any changes before and after the experiment. In addition, a paired $t$ test was conducted to identify the subjects' satisfaction with the condition of their skin before and after the experiment.

Table 1 Cosmetic ingredients applied to the group

\begin{tabular}{|c|c|c|c|c|c|}
\hline \multirow[t]{2}{*}{ Variable } & \multicolumn{2}{|l|}{ Base } & \multicolumn{2}{|l|}{ Active } & \multirow{2}{*}{$\begin{array}{l}\text { Total } \\
\text { unit } \\
(\%)\end{array}$} \\
\hline & Ingredient & Quantity (\%) & Ingredient & Quantity (\%) & \\
\hline \multirow[t]{6}{*}{ C/E group } & Water & 87.36 & Niacinamide & 2.00 & 100 \\
\hline & Glycerin & 3.00 & Adenosine & 0.04 & \\
\hline & Butylene glycol & 5.00 & & & \\
\hline & PEG-60 hydrogenated castor oil & 0.50 & & & \\
\hline & Isopropyl myristate & 0.10 & & & \\
\hline & 1,2-Hexanediol & 2.00 & & & \\
\hline
\end{tabular}




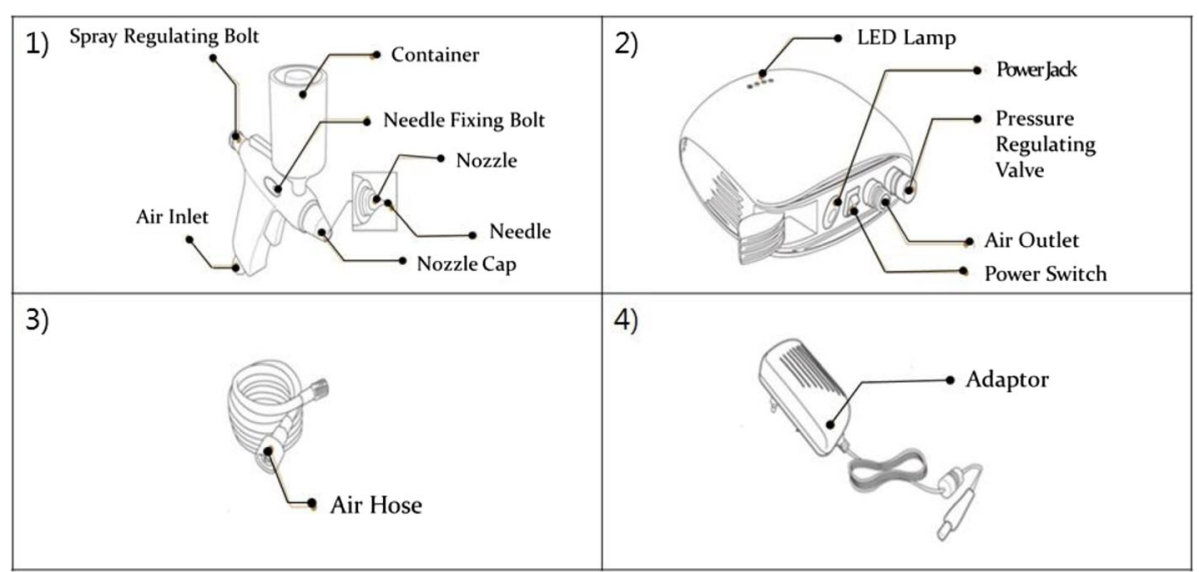

Fig. 1 (1) Air spray - put the liquid in the container and pull the lever to spray the liquid; the amount of injection can be adjusted according to the strength of pulling the lever. (2) Air compressor-the air compressor compresses a certain amount of air and delivers it to the spray gun. (3) Air hose - the air from the air compressor is supplied with the spray gun. (4) Adapter-its function is to charge the air compressor

\section{Results}

1. Verification of homogeneity between the groups Subjects' baseline facial skin conditions are presented in Table 2. Because these results did not show statistically significance differences between the two groups, pre-treatment group homogeneity was confirmed $(p>.05)$.

2. Changes in skin moisture level in each group Skin moisture level changes for groups $\mathrm{C}$ and $\mathrm{E}$ are shown in Table 3. On the forehead surface, group $\mathrm{C}$ showed a significant increase of $4.76(\mathrm{M})$ in mean moisture content, from $59.60(\mathrm{M})$ to $64.37(\mathrm{M})$ posttreatment $(p<.05)$. Group E showed an increase of 4.67(M) in mean moisture content, from 61.00(M) to $65.68(\mathrm{M})$ post-treatment. On the chin surface, group $\mathrm{C}$ showed a mean moisture increase of 1.88(M), from $62.57(\mathrm{M})$ to $64.45(\mathrm{M})$, and group $\mathrm{E}$ showed an increase of $2.15(\mathrm{M})$, from 63.47(M) to 65.62(M). For the right cheek, the mean moisture increase for group $\mathrm{C}$ was $2.66(\mathrm{M})$, from $67.60(\mathrm{M})$ to 70.27(M) post-treatment, and that for group $\mathrm{E}$ was 4.44(M), from 64.85(M) to 69.29(M). For the left cheek, group $\mathrm{C}$ showed an increase of 5.05(M), from $64.81(\mathrm{M})$ to $69.86(\mathrm{M})$, and group E showed an increase of 4.16(M), from 65.80(M) to 69.97(M).

3. Changes in skin color luminosity in each group Changes in skin color luminosity for groups $C$ and $\mathrm{E}$ are presented in Figs. 2 and 3. Group $C$ showed an increase of brightness in the region of the upper-

Table 2 Verification of homogeneity between $C$ and $E$ groups

\begin{tabular}{|c|c|c|c|c|c|c|}
\hline Variable & & & $\begin{array}{l}C(n=10) \\
M \pm S D\end{array}$ & $\begin{array}{l}\mathrm{E}(n=10) \\
\mathrm{M} \pm \mathrm{SD}\end{array}$ & $t$ & $p$ \\
\hline \multirow[t]{4}{*}{ Moisture } & Forehead & & $59.60 \pm 8.12$ & $61.00 \pm 6.38$ & -.429 & .673 \\
\hline & Jew & & $62.57 \pm 6.15$ & $63.47 \pm 8.57$ & -.268 & .792 \\
\hline & Rt. Cheek & & $67.60 \pm 5.82$ & $64.85 \pm 7.18$ & .941 & .359 \\
\hline & Lt. Cheek & & $64.81 \pm 10.51$ & $65.80 \pm 8.97$ & -.226 & .824 \\
\hline \multirow[t]{6}{*}{ Skin Color Value } & Rt. Lid Cheek & $L^{*}$ & $35.77 \pm 5.00$ & $36.64 \pm 3.60$ & -.446 & .661 \\
\hline & & $a^{*}$ & $18.20 \pm 1.77$ & $18.89 \pm 2.82$ & -.652 & .523 \\
\hline & & $b^{*}$ & $16.05 \pm 2.96$ & $17.10 \pm 3.11$ & -.778 & .447 \\
\hline & Lt. Lid Cheek & $L^{*}$ & $36.86 \pm 3.47$ & $35.81 \pm 3.37$ & .690 & .499 \\
\hline & & $a^{*}$ & $18.53 \pm 1.40$ & $19.90 \pm 2.09$ & -1.722 & .102 \\
\hline & & $b^{*}$ & $16.29 \pm 1.76$ & $15.66 \pm 3.38$ & .519 & .610 \\
\hline \multirow[t]{3}{*}{ Wrinkle } & Overall size & & $12.98 \pm 5.08$ & $13.21 \pm 4.98$ & -.102 & .920 \\
\hline & Depth & & $0.049 \pm 0.013$ & $0.055 \pm 0.018$ & -.802 & .433 \\
\hline & Width & & $1.13 \pm 0.18$ & $0.97 \pm 0.28$ & 1.461 & .161 \\
\hline
\end{tabular}


Table 3 Comparison of facial moisture (index: AU)

\begin{tabular}{|c|c|c|c|c|c|c|}
\hline \multirow[t]{2}{*}{ Variable } & \multirow[t]{2}{*}{ Group } & \multicolumn{2}{|c|}{ Measurement $(\mathrm{M} \pm \mathrm{SD})$} & \multirow[t]{2}{*}{$t_{1}-t_{2}$} & \multirow[t]{2}{*}{$t(p)$} & \\
\hline & & Before & After & & & \\
\hline \multirow[t]{2}{*}{ Forehead } & $C(n=10)$ & $59.60 \pm 8.12$ & $64.37 \pm 5.83$ & $-4.76 \pm 6.60$ & -2.284 & $\left(.048^{*}\right)$ \\
\hline & $\mathrm{E}(n=10)$ & $61.00 \pm 6.38$ & $65.68 \pm 5.96$ & $-4.67 \pm 8.01$ & -1.846 & $(.098)$ \\
\hline \multirow[t]{2}{*}{ Jew } & $C(n=10)$ & $62.57 \pm 6.15$ & $64.45 \pm 4.56$ & $-1.88 \pm 7.31$ & -.813 & $(.437)$ \\
\hline & $\mathrm{E}(n=10)$ & $63.47 \pm 8.57$ & $65.62 \pm 5.27$ & $-2.15 \pm 7.10$ & -.959 & $(.363)$ \\
\hline \multirow[t]{2}{*}{ Rt. Cheek } & $C(n=10)$ & $67.60 \pm 5.82$ & $70.27 \pm 4.86$ & $-2.66 \pm 5.06$ & -1.663 & $(.131)$ \\
\hline & $E(n=10)$ & $64.85 \pm 7.18$ & $69.29 \pm 4.78$ & $-4.44 \pm 6.54$ & -2.147 & $(.060)$ \\
\hline \multirow[t]{2}{*}{ Lt. Cheek } & $C(n=10)$ & $64.81 \pm 10.51$ & $69.86 \pm 5.20$ & $-5.05 \pm 10.39$ & -1.537 & (.159) \\
\hline & $E(n=10)$ & $65.80 \pm 8.97$ & $69.97 \pm 5.04$ & $-4.16 \pm 8.01$ & -1.645 & $(.134)$ \\
\hline
\end{tabular}

${ }^{*} p<.05$

Abbreviations were the same as Table 2 .

right cheekbone of $11.0 \%$, from $35.77(\mathrm{M})$ to 39.71(M) post-treatment, and group E exhibited a statistically significant increase of $6.6 \%$, from 36.64(M) to 39.06(M) $(p<.05)$. In terms of red color intensity in the same region, group $\mathrm{C}$ showed an increase of $0.2 \%$, from $18.20(\mathrm{M})$ to $18.23(\mathrm{M})$ post-treatment, and group E showed a statistically significant decrease of $16.3 \%$, from $18.89(\mathrm{M})$ to $15.80(\mathrm{M})(p<.05)$. In terms of yellow color intensity in the same region, group $\mathrm{C}$ showed a decline of $4.4 \%$, from $16.05(\mathrm{M})$ to $15.34(\mathrm{M})$ post-treatment, whereas group E exhibited an increase of $5.9 \%$, from 17.10(M) to 18.11(M). In terms of the level of brightness in the upper-left cheekbone, group $\mathrm{C}$ showed an increase of $4.2 \%$, from $36.86(\mathrm{M})$ to 38.42(M) post-treatment, and group E exhibited a statistically significant increase of $8.3 \%$, from $35.81(\mathrm{M})$ to $38.81(\mathrm{M})(p<.05)$. In terms of red color intensity in the same region, group $\mathrm{C}$ showed an increase of $2.9 \%$, from $18.53(\mathrm{M})$ to $19.06(\mathrm{M})$ post-treatment, and group E exhibited a statistically significant increase of $18.0 \%$, from $19.90(\mathrm{M})$ to 16.30(M) $(p<.001)$. Meanwhile, group $C$ showed a decrease of $8.1 \%$, from $16.29(\mathrm{M})$ to $14.96(\mathrm{M})$ posttreatment, and group E showed a statistically significant increase of $15.9 \%$, from $15.66(\mathrm{M})$ to $18.16(\mathrm{M})$ $(p<.05)$ in yellow color intensity in the same region.

4. Changes in main wrinkles in each group The changes in wrinkles around the left eye for groups $C$ and $E$ are shown in Table 4 and Fig. 4. In group $\mathrm{C}$, the size of the main wrinkles significantly decreased by $16.6 \%$, from $12.98(\mathrm{M})$ to $10.83(\mathrm{M})$ post-treatment $(p<.01)$. In group $\mathrm{E}$, there was a statistically significant decrease of $20.9 \%$, from 13.21(M) to $10.45(\mathrm{M})(p<.01)$. In group $\mathrm{C}$, the

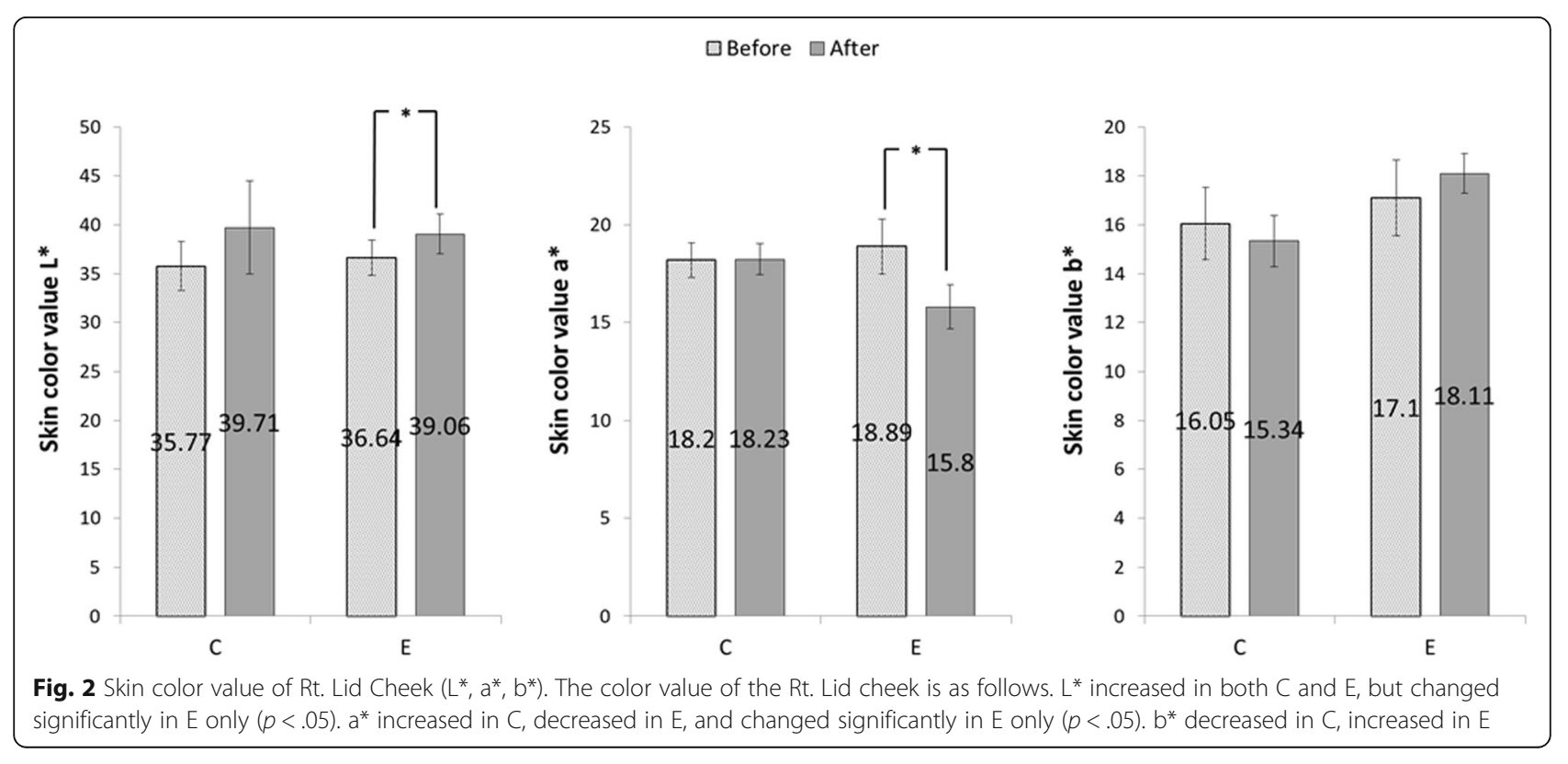




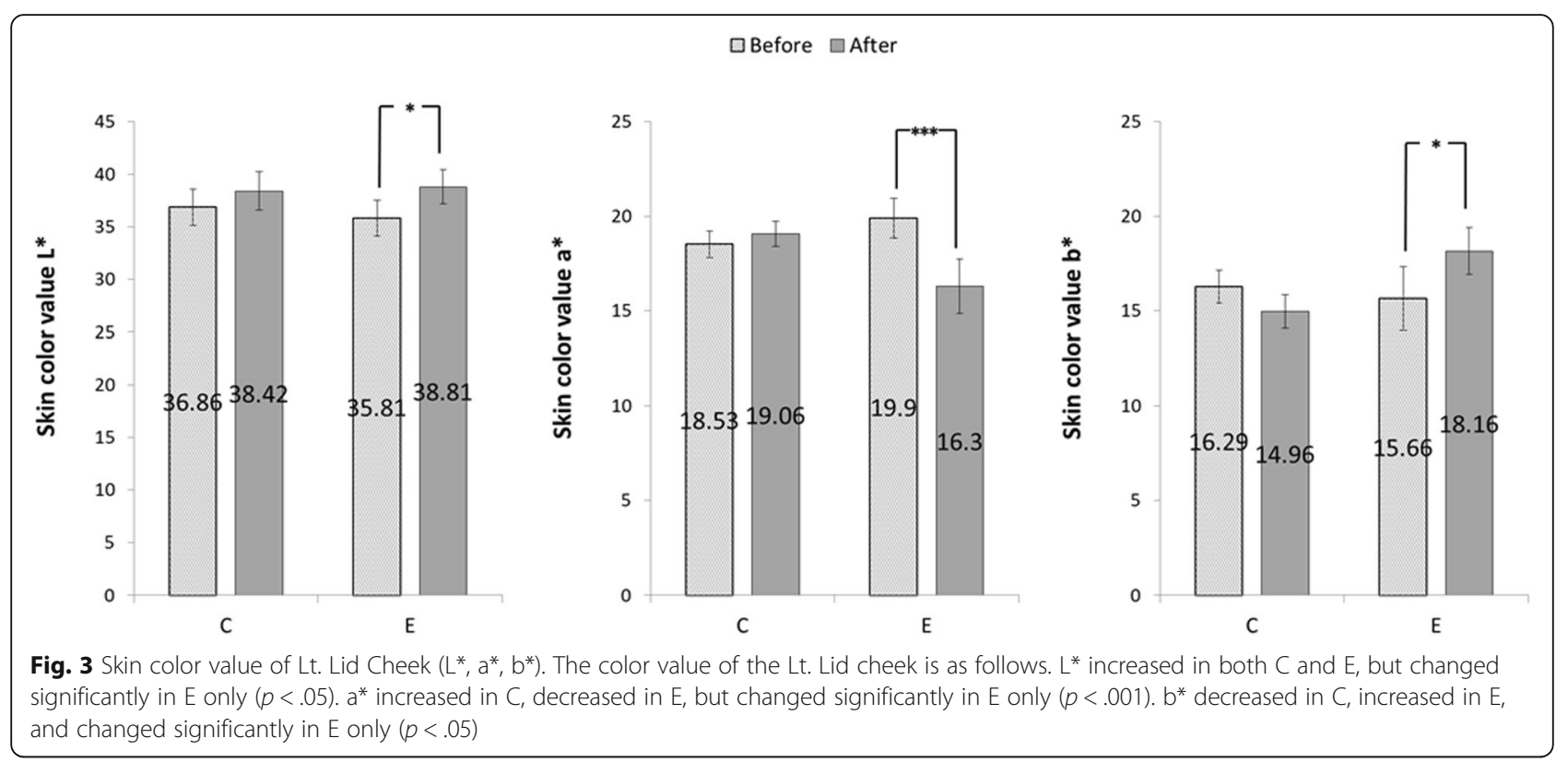

depth of the main wrinkles significantly decreased by $10.2 \%$, from $0.049(\mathrm{M})$ to $0.043(\mathrm{M})$ posttreatment $(p<.05)$. In group $\mathrm{E}$, the depth significantly decreased by $12.7 \%$, from $0.055(\mathrm{M})$ to $0.047(\mathrm{M})(p<.05)$. In group $\mathrm{C}$, the width of the main wrinkles significantly decreased by $8.0 \%$, from $1.13(\mathrm{M})$ to $1.04(\mathrm{M})$ post-treatment $(p<.01)$. In group $\mathrm{E}$, the width significantly decreased by $9.3 \%$, from $0.97(\mathrm{M})$ to $0.88(\mathrm{M})(p<.01)$. Consequently, both groups showed statistically significant improvements in the overall size, depth, and width of the main wrinkles. However, group $\mathrm{E}$ achieved relatively more improvement in all variables compared to group $\mathrm{C}$, which may point to the effectiveness of the air brush.

5. Changes in subjective satisfaction with skin conditions in each group

The reliability of the satisfaction evaluation tool used in this study is presented in Table 5. And subjective satisfaction ratings are presented in Table 6. The selected items were scored based on a 5-point scale as follows: 1 point for "very unsatisfied," 2 points for "unsatisfied," 3 points for "average," 4 points for "satisfied," and 5 points for "very satisfied." A higher score corresponds to a higher level of satisfaction. In addition, the same items were administered to each subject pre- and post-treatment to treatment-related changes in perceived satisfaction.

In the items related to skin dryness and tightness, group $\mathrm{C}$ registered a statistically significant increase of $1.60(\mathrm{M})$ in satisfaction, from $2.20(\mathrm{M})$ to $3.80(\mathrm{M})$ post-treatment $(p<.01)$. Group $\mathrm{E}$ also showed significant increase by $1.90(\mathrm{M})$, from $2.21(\mathrm{M})$ to $4.00(\mathrm{M})(p<.01)$. On items related to the formation of dead skin cells, group $\mathrm{C}$ showed a statistically significant increase of $1.40(\mathrm{M})$ in satisfaction, from $2.80(\mathrm{M})$ to $4.20(\mathrm{M})(p<.01)$ post-treatment. Group E also exhibited a statistically significant

Table 4 Comparison of facial wrinkle

\begin{tabular}{|c|c|c|c|c|c|c|}
\hline \multirow[t]{2}{*}{ Variable } & \multirow[t]{2}{*}{ Group } & \multicolumn{2}{|l|}{$\begin{array}{l}\text { Measurement } \\
(\mathrm{M} \pm \mathrm{SD})\end{array}$} & \multirow[t]{2}{*}{$t_{1}-t_{2}$} & \multirow[t]{2}{*}{$t(p)$} & \\
\hline & & Before & After & & & \\
\hline \multirow[t]{2}{*}{ Overall size (AU) } & $C(n=10)$ & $12.98 \pm 5.08$ & $10.83 \pm 5.19$ & $2.15 \pm 1.36$ & 4.984 & $\left(.001^{* *}\right)$ \\
\hline & $\mathrm{E}(n=10)$ & $13.21 \pm 4.98$ & $10.45 \pm 4.03$ & $2.76 \pm 2.51$ & 3.478 & $\left(.007^{* *}\right)$ \\
\hline \multirow[t]{2}{*}{ Depth (mm) } & $C(n=10)$ & $0.049 \pm 0.013$ & $0.043 \pm 0.016$ & $0.005 \pm 0.006$ & 3.023 & $\left(.014^{*}\right)$ \\
\hline & $E(n=10)$ & $0.055 \pm 0.018$ & $0.047 \pm 0.014$ & $0.007 \pm 0.009$ & 2.475 & $\left(.035^{*}\right)$ \\
\hline \multirow[t]{2}{*}{ Width (mm) } & $C(n=10)$ & $1.13 \pm 0.18$ & $1.04 \pm 0.21$ & $0.09 \pm 0.07$ & 4.150 & $\left(.002^{* *}\right)$ \\
\hline & $E(n=10)$ & $0.97 \pm 0.28$ & $0.88 \pm 0.25$ & $0.09 \pm 0.06$ & 5.010 & $\left(.001^{* *}\right)$ \\
\hline
\end{tabular}

${ }^{*} p<.05,{ }^{* *} p<.01$

Abbreviations were the same as Table 2 

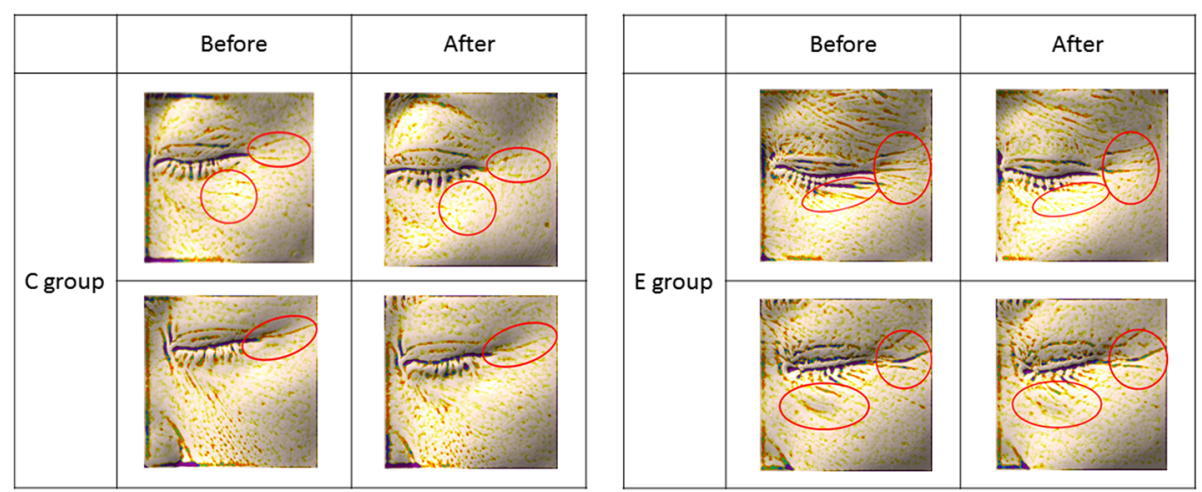

Fig. 4 Comparison of main wrinkles of the Lt. Eye. Main wrinkles of Lt. Eye have been indicated. Overall size, depth, and width of wrinkles decreased significantly in both $\mathrm{C}$ and $\mathrm{E}$; however, it decreased more in $\mathrm{E}$ than in $\mathrm{C}$

increase of $1.70(\mathrm{M})$, from $2.50(\mathrm{M})$ to $4.20(\mathrm{M})$ post-treatment $(p<.01)$. In the items related to skin roughness, group $\mathrm{C}$ achieved a statistically significant improvement of $1.70(\mathrm{M})$ in satisfaction, from $2.70(\mathrm{M})$ to $4.40(\mathrm{M})$ post-treatment $(p<.01)$. Group $\mathrm{E}$ also registered a statistically significant increase of $1.40(\mathrm{M})$ in satisfaction, from $2.90(\mathrm{M})$ to $4.30(\mathrm{M})(p<.01)$. In all items related to skin moisture, all subjects were "unsatisfied" with a mean score of fewer than 3 points pre-treatment, but all stated they were "satisfied" post-treatment, with a mean score of 4.15 points. In addition, these changes were statistically significant for all items. Given that the subjects were middle-aged women in their 30s-50s, this study showed significant improvements in overall satisfaction with skin moisture, even though the research was done in the late autumn and winter between November and February.

In the items related to skin pigmentation such as stains, freckles, and blemishes, group C showed a statistically significant increase of $2.50(\mathrm{M})$ in satisfaction, from $1.50(\mathrm{M})$ to $4.00(\mathrm{M})$ post-treatment $(p<.001)$. Group E also showed a statistically significant increase of $2.30(\mathrm{M})$ in satisfaction, from 1.60(M) to 3.90(M) $(p<.001)$. In the items related to the evenness of skin tone, group $\mathrm{C}$ showed a significant increase of $2.30(\mathrm{M})$ in satisfaction, from $1.90(\mathrm{M})$ to 4.20(M) post-treatment $(p<.001)$. Group E also exhibited a statistically significant increase of $1.80(\mathrm{M})$ in satisfaction, from $2.20(\mathrm{M})$ to $4.00(\mathrm{M})(p<.01)$. In the items related to

Table 5 Reliability of the measurement tool

\begin{tabular}{llll}
\hline Category & & $\begin{array}{l}\text { The number of } \\
\text { question }\end{array}$ & Alpha \\
\hline Satisfaction of skin condition & Hydration & 3 & .940 \\
& Pigmentation & 3 & \\
& Elasticity & 3 & \\
& Skin sensitization & 1 & \\
\hline
\end{tabular}

skin whitening, all subjects were "unsatisfied" with a mean score of $1.80(\mathrm{M})$ pre-treatment, but they were "satisfied" with a mean score of $4.0(\mathrm{M})$ post-treatment. These changes were statistically significant for all items under the category. Overall, subjects showed higher levels of satisfaction with their level of skin whitening than with their ratings of skin moisture. As presented in Figs. 2 and 3 , these results appear to verify the effectiveness of niacinamide as a whitening agent.

In the items related to skin redness, group $\mathrm{C}$ showed a statistically significant increase of $0.70(\mathrm{M})$ in satisfaction, from 3.30(M) to 4.00(M) post-treatment $(p<.005)$. Group $E$ also exhibited a statistically significant increase of $1.00(\mathrm{M})$ in satisfaction, from $3.10(\mathrm{M})$ to $4.10(\mathrm{M})(p<.01)$. Unlike the earlier results describing overall satisfaction with hyperpigmentation, group E showed higher overall satisfaction with hyperpigmentation compared to group C. This finding might relate to observations of reduced skin redness following air brushing. Skin redness most clearly contrasts the two groups when verifying air brush effectiveness.

In the items related to pores, group $C$ showed a statistically significant increase of $1.70(\mathrm{M})$ in satisfaction, from $2.20(\mathrm{M})$ to $3.90(\mathrm{M})$ post-treatment $(p<.01)$. Group E also exhibited a statistically significant increase of $1.50(\mathrm{M})$, from $2.40(\mathrm{M})$ to $3.90(\mathrm{M})(p<.01)$. In the items related to skin elasticity, group $\mathrm{C}$ showed a statistically significant increase of $1.90(\mathrm{M})$ in satisfaction, from $1.70(\mathrm{M})$ to $3.60(\mathrm{M})$ post-treatment $(p<.001)$. Group E also showed a statistically significant increase of $2.10(\mathrm{M})$ in satisfaction, from $1.90(\mathrm{M})$ to $4.00(\mathrm{M})(p<.001)$. In the items related to wrinkles, group $\mathrm{C}$ showed a statistically significant increase of $1.90(\mathrm{M})$ in satisfaction, from $1.70(\mathrm{M})$ to $3.60(\mathrm{M})$ post-treatment $(p<.001)$. Group E also exhibited a statistically significant increase of $2.00(\mathrm{M})$ in satisfaction, from $1.80(\mathrm{M})$ to $3.80(\mathrm{M})(p<.001)$. As shown in Table 4 , these results appear to verify the effectiveness of adenosine as an anti-wrinkle agent. 
Table 6 Satisfaction after use

\begin{tabular}{|c|c|c|c|c|c|c|}
\hline \multirow[t]{2}{*}{ Variable } & \multirow[t]{2}{*}{ Group } & \multicolumn{2}{|c|}{ Measurement $(\mathrm{M} \pm \mathrm{SD})$} & \multirow[t]{2}{*}{$t_{1}-t_{2}$} & \multirow[t]{2}{*}{$t(p)$} & \\
\hline & & Before & After & & & \\
\hline \multirow[t]{2}{*}{ Dehydrated } & $C(n=10)$ & $2.20 \pm 0.78$ & $3.80 \pm 1.03$ & $-1.60 \pm 1.42$ & -3.539 & $\left(.006^{* *}\right)$ \\
\hline & $\mathrm{E}(n=10)$ & $2.21 \pm 0.56$ & $4.00 \pm 0.81$ & $-1.90 \pm 1.19$ & -5.019 & $\left(.001^{* *}\right)$ \\
\hline \multirow[t]{2}{*}{ Flaking skin } & $C(n=10)$ & $2.80 \pm 0.42$ & $4.20 \pm 0.78$ & $-1.40 \pm 0.96$ & -4.583 & $\left(.001^{* *}\right)$ \\
\hline & $\mathrm{E}(n=10)$ & $2.50 \pm 0.70$ & $4.20 \pm 0.78$ & $-1.70 \pm 1.33$ & -4.019 & $\left(.003^{* *}\right)$ \\
\hline \multirow[t]{2}{*}{ Rough skin } & $C(n=10)$ & $2.70 \pm 0.82$ & $4.40 \pm 0.69$ & $-1.70 \pm 1.15$ & -4.636 & $\left(.001^{* *}\right)$ \\
\hline & $\mathrm{E}(n=10)$ & $2.90 \pm 1.10$ & $4.30 \pm 0.67$ & $-1.40 \pm 1.17$ & -3.772 & $\left(.004^{* *}\right)$ \\
\hline \multirow[t]{2}{*}{ Hyper-pigmentation } & $C(n=10)$ & $1.50 \pm 0.52$ & $4.00 \pm 0.94$ & $-2.50 \pm 0.97$ & -8.135 & $\left(.000^{* * *}\right)$ \\
\hline & $\mathrm{E}(n=10)$ & $1.60 \pm 0.69$ & $3.90 \pm 0.99$ & $-2.30 \pm 1.33$ & -5.438 & $\left(.000^{* * *}\right)$ \\
\hline \multirow[t]{2}{*}{ Even skin tone } & $C(n=10)$ & $1.90 \pm 0.31$ & $4.20 \pm 0.91$ & $-2.30 \pm 0.94$ & -7.667 & $\left(.000^{* * *}\right)$ \\
\hline & $\mathrm{E}(n=10)$ & $2.20 \pm 0.63$ & $4.00 \pm 0.94$ & $-1.80 \pm 1.22$ & -4.630 & $\left(.001^{* *}\right)$ \\
\hline \multirow[t]{2}{*}{ Blush } & $C(n=10)$ & $3.30 \pm 1.25$ & $4.00 \pm 0.81$ & $-0.70 \pm 0.94$ & -2.333 & $\left(.045^{*}\right)$ \\
\hline & $\mathrm{E}(n=10)$ & $3.10 \pm 0.87$ & $4.10 \pm 0.56$ & $-1.00 \pm 0.94$ & -3.354 & $\left(.008^{* *}\right)$ \\
\hline \multirow[t]{2}{*}{ Pore condition } & $C(n=10)$ & $2.20 \pm 0.78$ & $3.90 \pm 0.73$ & $-1.70 \pm 1.05$ & -5.075 & $\left(.001^{* *}\right)$ \\
\hline & $\mathrm{E}(n=10)$ & $2.40 \pm 0.69$ & $3.90 \pm 0.56$ & $-1.50 \pm 0.97$ & -4.881 & $\left(.001^{* *}\right)$ \\
\hline \multirow[t]{2}{*}{ Skin elasticity } & $C(n=10)$ & $1.70 \pm 0.82$ & $3.60 \pm 1.07$ & $-1.90 \pm 1.10$ & -5.460 & $\left(.000^{* * *}\right)$ \\
\hline & $\mathrm{E}(n=10)$ & $1.90 \pm 0.73$ & $4.00 \pm 1.05$ & $-2.10 \pm 0.73$ & -9.000 & $\left(.000^{* * *}\right)$ \\
\hline \multirow[t]{2}{*}{ Wrinkle } & $C(n=10)$ & $1.70 \pm 0.94$ & $3.60 \pm 1.07$ & $-1.90 \pm 0.73$ & -8.143 & $\left(.000^{* * *}\right)$ \\
\hline & $\mathrm{E}(n=10)$ & $1.80 \pm 0.63$ & $3.80 \pm 0.91$ & $-2.00 \pm 0.94$ & -6.708 & $\left(.000^{* * *}\right)$ \\
\hline \multirow[t]{2}{*}{ Skin sensitization } & $C(n=10)$ & $3.50 \pm 1.08$ & $3.70 \pm 0.94$ & $-0.20 \pm 1.03$ & -.612 & $(.555)$ \\
\hline & $\mathrm{E}(n=10)$ & $3.70 \pm 0.82$ & $4.20 \pm 0.91$ & $-0.50 \pm 1.26$ & -1.246 & $(.244)$ \\
\hline
\end{tabular}

${ }^{*} p<.05,{ }^{* *} p<.01,{ }^{* * *} p<.001$

Abbreviations were the same as Table 2

In the items related to skin sensitivity and allergies, group $\mathrm{C}$ showed a statistically significant increase of $0.20(\mathrm{M})$ in satisfaction, from $3.50(\mathrm{M})$ to $3.70(\mathrm{M})$ post-treatment. Group E also exhibited a statistically significant increase of $0.50(\mathrm{M})$ in satisfaction, from $3.70(\mathrm{M})$ to $4.20(\mathrm{M})$. There were no statistically significant post-treatment changes relating to skin sensitivity and allergies.

The items related to pigmentation such as stains, freckles, and blemishes, the items related to skin elasticity, and the items related to wrinkles showed the lowest levels of satisfaction prior to the application; interestingly, these items showed the overall greatest changes in satisfaction post-treatment. Certainly, there could be minor differences in the level of skin condition improvement between measures, using skin analysis devices and the subjects' subjective evaluations. However, as the degree to which individuals were satisfied with their skin is essentially based on naked-eye observations, these observations are inherently subjective. For this reason, certain differences between the subjects' own evaluations and objective data could be further validated. Nevertheless, the present study proved the functional utility of niacinamide and adenosine, based on both objective and subjective measures. These findings speak to this study's significance.

\section{Discussion}

Kim (2004) described the usefulness of niacinamide as a moisturizing agent. A study by Draelos et al. (2005) reported that a 4-week application of a moisturizer containing $2 \%$ niacinamide to the forearms of subjects in the experimental group resulted in a statistically significant increase in the mean moisture level of the skin compared to the control group $(p<.01)$. A study by Draelos $(2008)$ reported that a 24-day application of a topical ointment containing $2 \%$ niacinamide to the forearms of the subjects in the experimental group led to a statistically significant decrease in transepidermal water loss compared to the control group $(p<.002)$. Adenosine, the second ingredient in the test agent, may have increased the dermal distribution of collagen, which could be attributed to adenosine's ability to increase collagen synthesis and inhibit collagen disintegration (Ha et al. 1998; Sohn et al. 2007). Thus, adenosine can increase skin moisture because of the moisture-friendly characteristics of collagen. In the present study, the observed increases in skin moisture may have resulted from the complex interactions of niacinamide and adenosine contained in the test agent.

Niacinamide is a functional whitening ingredient that inhibits the production of melanin by suppressing tyrosinase secretion (Go et al. 2013). A study by Hakozaki et 
al. (2002), which was conducted in an in vitro co-culture experiment, indicated that niacinamide effectively inhibited the transfer of melanosome by up to $68 \%$. Based on this finding, our finding of increased brightness on both the left and right sides was attributed to the functional whitening effects of niacinamide.

Park et al. (2010) administered vitamin C to subjects twice a week over a 6-week period. Here, the experimental group underwent ion electrophoresis coupled with a micro-spray device, whereas the control group received only ion electrophoresis. The authors measured levels of pigmentation in both groups using the RSA (Robo Skin Analyzer CS50, Inforward, Japan). After receiving their respective treatments 12 times, the experimental group showed a statistically significant decrease of $4.38 \pm 3.85$ $(\mathrm{M} \pm \mathrm{SD})$ in the number of small-particle pigments $(p$ $<.05)$, but the control group exhibited an increase of 5.63 \pm 8.90 ( $p=.117)$. In terms of the number of large-particle pigments, the experimental group exhibited a statistically significant decrease of $10.75 \pm 7.44(p<.01)$ and the control group showed an increase of $5.50 \pm 10.53(p=.183)$. These results suggest that using small particles that are sprayed increases the absorption of water-soluble cosmetic substances. In the present study, only group E showed a statistically significant change in the level of brightness, thereby suggesting that the air brush was effective.

Skin redness is caused by hemoglobin in the blood vessels underneath; close distribution of capillaries to the epidermis provides the face with a red tone (Yoo and Lee 2010). In this study, group $C$ showed increased skin redness $(+16.3 \%)$ on both the left and right sides, whereas group $E$ showed statistically significant decreases $(-18.0 \%)$ in skin redness on the left and right sides. This result probably occurred because of reductions in skin surface temperature due to the air brush stimulation of the capillaries, which in turn produced reduced redness. In addition, as described earlier, increased distribution of collagens in the skin due to adenosine may have increased the physical distance between the capillaries and the skin surface.

Blueish tones in the lower orbit of the eye can be caused by complex factors such as structural problems arising from fat thickness imbalances, blood vessels or lower tissue layers visualized through thin skin tissues, and pigmentation (Shin et al. 2011). In the present study, group $C$ showed decreases in skin yellowing on both the left and right sides, while group E exhibited increased yellowing on both sides. In other words, the blue color intensity may have increased in group $\mathrm{C}$ but decreased in group $\mathrm{E}$. This can be explained in line with the observed decreases in skin redness due to collagen distribution and capillary contraction.

Park and Lee (2015) implemented a skin care program using a water-jet, and the program was administered two times in an interval of 2 days. Then, the changes in the wrinkles were measured based on the number of pixels by employing a shadow detection method. As a result, fine wrinkles around the orbicularis oris muscle showed a statistically significant reduction of $5.14 \pm 2.90$ pixels $(p<.001)$. In this study, Park and Lee (2015) used a water-jet in conjunction with a skin care program in the subjects and measured the changes $20 \mathrm{~min}$ after the final treatment. This differs from the current study method where air brushes were used in the home setting. However, in both studies, statistically significant wrinkle improvements were achieved over the entire face.

\section{Conclusions}

This study attempted to verify the physiological activities of niacinamide as a functional whitening agent and adenosine as an anti-wrinkle agent, as well as the effectiveness of the air brush as a skin care device.

The study's findings showed increases in moisture content among all subjects. This may have been because the moisturizing effects of niacinamide were coupled with adenosine-induced increases in skin collagen content. This caused collagens, which are typically moisture-friendly, to further increase the moisture content of the skin. Both groups showed increased skin brightness post-treatment. These changes may have occurred because niacinamide acts as a functional whitening agent, which suppresses the production of melanin and the transfer of melanisome. However, statistically significant increases in the skin brightness were found only in group E. Consequently, these changes may actually reflect the effect of spraying fine particles using an air brush. In terms of the red color intensity, group $\mathrm{C}$ showed an increase, while group $\mathrm{E}$ showed a significant decrease. The increased distribution of collagens due to adenosine application may have increased the physical distance between the capillaries and the skin surface. In addition, temperature decrease on the skin surface caused by the air brush may have effectively constricted the capillaries. This result seems to agree with our observation that group $\mathrm{C}$ showed an increase in blue intensity, whereas group $\mathrm{E}$ showed a decrease in blue intensity. Both groups achieved statistically significant improvements in the overall size, depth, and width of the main wrinkles. This may reaffirm the beneficial effects of adenosine. However, the relatively greater improvements observed in group E compared to group C appeared to verify the usefulness of the air brush as a skin care device. When we evaluated patient satisfaction, items related to pigmentation and skin elasticity showed the greatest changes. This result was meaningful and, once again, appeared to validate the use of niacinamide and adenosine for improving perceived skin satisfaction. 
The present study also verified the usefulness of niacinamide and adenosine as they relate to skin physiology, and the effectiveness of the air brush as a skin care device. Existing studies on skin care devices are limited in that they were mostly conducted within expert-run programs. Therefore, future studies may be required to verify the effects of skin care devices within the home environment. In addition, while studies on the dermal absorption of water-soluble substances have thus far been confined to the application of ionospheresis, some previous studies have suggested the potential for enhanced dermal absorption of water-soluble substances through physical actions (Park et al. 2010).

The dermis only absorbs approximately $0.1-0.5 \%$ of the total volume of water-soluble substances. These substances are quickly absorbed via sebaceous glands and then activated (Yoo and Lee 2010). Additional studies are needed on the dermal absorption of water-soluble substances. In particular, studies using air brushes in order to induce physical changes through air pressuredriven spray of fine particles are needed.

\section{Abbreviations}

LED: Light-emitting diode; MFDS: Ministry of Food and Drug Safety

\section{Funding}

This study was performed through a joint research contract between Dasan C \& Tech and Aphrozone in 2017 and was funded by Aphrozone.

\section{Authors' contributions}

HJK designed the study and wrote the manuscript. MSJ reviewed the study and edited the manuscript. JMS and YKH performed the research background such as the experiments and data collection. All authors read and approved the final manuscript.

\section{Ethics approval and consent to participate}

This study was approved by the Institutional Review Board of the Korea National Institute for Bioethics Policy following a comprehensive review of

\section{Consent for publication}

Not applicable.

\section{Competing interests}

The authors declare that they have no competing interests. study-related procedures (P01-201711-13-002).

Ha YH, Yu SU, Kim DS, Lim SJ, Choi YW. Hydrolysis, skin permeation and in vivo whitening effect of kojic acid monostearate as an antimelanogenic agent. 1998:42:39-45. http://www.riss.kr/link?id=A100402513 Accessed 1998.

Hakozaki T, Minwalla L, Zhuang J, Chhoa M, Matsubara A, Miyamoto K, et al. The effect of niacinamide on reducing cutaneous pigmentation and suppression of melanosome transfer. Br J Dermatol. 2002;14:20-31. http://www.riss.kr/ link?id=032050979 Accessed 2002

Han SM, Hong IP, Woo SO, Cheon SN, Han CS. The effect of cosmetic included purified bee venom on the improvement of skin wrinkle. 2015;21:288-292. http://www.riss.kr/link?id=A100486555 Accessed 2015.

Jo SY, Hwang SM. A study of effects of gap between actual age and selfperceived age in middle-age women on their appearance management behavior and self-esteem. Kor J Aesthet Cosmetol. 2013;11:1137-46. http:// www.riss.kr/link?id=A99908555 Accessed 2013.12

Kim EH. A study on professional unmarried men's clothing purchase-appearance management behavior and self-respect. Seoul, Korea: Unpublished master's thesis, Kyunghee University; 2006. p. 1-2. http://www.riss.kr/link?id= T10697500 Accessed 2006.08

Kim JE. Stabilization of facial skin physiological parameters after exposure to summer and winter climatic condition. Theses for Master's Degree at Korea University, 2007:43-44. http://www.riss.kr/link?id=T11086500 Accessed 2007.08.

Kim JH, Park OL, Lee DC. The study on the consumer's clothing satisfaction and fashion consciousness according to shopping orientation of male consumers. J Korean Data Anal Soc. 2005;7:533-48. http://www.riss.kr/link?id=A101600342 Accessed Apr 2005

Kim KS, Gang SM. The skin safety and effects of the fermented broth of Lactobacillus rhamnosus for improving the neck skin. J Korean Acad Nurs. 2017;23:101-14. http://www.riss.kr/link?id=A103064107 Accessed 2017

Kim KY, Bea YK, Lee EJ, Kim SM, Kim EA, Ahn SL. Essence cosmetology. Paju-si: Jigu Publishing Co; 2014. p. 161. http://www.riss.kr/link?id=M13421745 Accessed 2014

Kim YM. Medical skin care2. Seoul: Imsong Books; 2004. p. 246-7. http://www.riss. kr/link?id=M9369963 Accessed 2004

Lee JH, Moon JS, Choi TB. Effect of the cosmetics containing schizandra chinesis extracts on the skin of the middle aged women. J Korea Soc Cosmetol. 2013; 19:634-41. http://www.riss.kr/link?id=T13244819 Accessed 2013.8

Lee KJ, Kim HJ. Correlation of body image, self-esteem, and appearance management behavior. Kor J Aaesthet Cosmetol. 2015;13:203-11. http:// www.riss.kr/link?id=A100537798 Accessed 2015

Park JY, Kang SM, Lee OK. Effect of fine particles injection by vitamin C on the skin change. Kor J Aesthet Cosmetol. 2010;8:253-62. http://www.riss.kr/ link?id=A82373498 Accessed 2010

Park KS, Lee HH. Development of a water sprayer for skin care and its effects on moisture and wrinkle improvements. Kor J Aaesthet Cosmetol. 2015;13:60313. http://www.earticle.net/article.aspx?sn=257397 Accessed 2015

Safire W. On language; lookism. In: The New York Times Magazine; 2000. https:// www.nytimes.com/2000/08/27/magazine/the-way-we-live-now-8-27-00-onlanguage-lookism.html Accessed 27 Aug 2000.

Shin Jl, Kwon 1O, Kim CY. Strategy for the treatment of infraorbital dark circles. 2011;17:91-98. http://www.riss.kr/link?id=A104566924 Accessed 2011.

Sohn ED, Hwang JS, Chang IS. R \& D trend of functional anti-wrinkle cosmetics. News Inf Chem Eng. 2007;25:133-8. http://www.riss.kr/link?id=A75313705 Accessed 2007

Yoo EA, Lee HA. Rediscovery of cosmetics, vol. 41. Seoul: Sungshin Women's University Press; 2010. p. 59-61. http://www.riss.kr/link?id=M12183745 Accessed 2010

\section{Publisher's Note}

Springer Nature remains neutral with regard to jurisdictional claims in published maps and institutional affiliations.

Received: 5 June 2018 Accepted: 22 August 2018

Published online: 17 September 2018

\section{References}

Draelos ZD. Clinical situations conducive to proactive skin health and anti-aging improvement. J Investig Dermatol Symp Proc. 2008;13:25-7. http://www.riss. kr/link?id=048885692 Accessed 2008

Draelos ZD, Ertel K, Berge C. Niacinamide-containing facial moisturizer improves skin barrier and benefits subjects with rosacea. Cutis. 2005;76:135-41. http:// www.riss.kr/link?id=043267714 Accessed 2005

Go HJ, Kim NS, Kim EH, Um MS, Oh JS. New cosmetology. Seoul: Gadam books; 2013. p. 110-1. http://www.riss.kr/link?id=M13762516 Accessed 2013
Ready to submit your research? Choose BMC and benefit from:

- fast, convenient online submission

- thorough peer review by experienced researchers in your field

- rapid publication on acceptance

- support for research data, including large and complex data types

- gold Open Access which fosters wider collaboration and increased citations

- maximum visibility for your research: over $100 \mathrm{M}$ website views per year

At $\mathrm{BMC}$, research is always in progress.

Learn more biomedcentral.com/submission 